\title{
INVESTIGAÇÃO DAS MANIFESTAÇÕES PATOLÓGICAS NOS PILARES DE UM VIADUTO NA CIDADE DE SALVADOR/BA
}

\author{
XAVIER, GUSTAVO DO NASCIMENTO \\ Estudante Engenharia Civil \\ Universidade do Estado da Bahia - UNEB \\ Bahia; Brasil \\ gusnavier@gmail.com
}

\author{
ANJOS, TELMA DIAS SILVA DOS \\ Professora \\ Universidade do Estado da Bahia - UNEB \\ Bahia; Brasil \\ telmadias@uneb.br
}

\author{
PEREIRA, TÂNIA REGINA DIAS SILVA \\ Professora \\ Universidade do Estado da Bahia - UNEB \\ Bahia; Brasil \\ tanreg.uneb@gmail.com
}

\author{
SARAIVA, ANA GABRIELA LIMA \\ Professora \\ Universidade do Estado da Bahia - UNEB \\ Bahia; Brasil \\ aglima@uneb.br
}

\section{RESUMO}

Os viadutos são estruturas de engenharia consideradas "Obra de Arte" por possibilitarem que uma estrada transponha vales, grotas e vias de tráfego nos centros urbanos. Essas construções são relevantes para o meio urbano, pois permitem ao usuário conectar-se a diferentes locais dentro da cidade com certa rapidez facilitando a mobilidade urbana. Dessa forma, o presente artigo tem como objetivo abordar as manifestações patológicas encontradas nos pilares de concreto armado em um viaduto localizado em importante via de acesso na cidade de Salvador-BA, bem como discorrer sobre as possíveis origens e os riscos que podem trazer aos usuários, já que a segurança fica comprometida. A metodologia utilizada consistiu na técnica de pesquisa bibliográfica e documental, através da análise do problema, refletindo sobre as prováveis causas, consequências e formas de prevenção de modo a minimizar tais ações deteriorantes. Foi realizada visita "in loco", a fim de diagnosticar por meio de inspeção visual as patologias que comprometem o bom funcionamento da estrutura. Cabe ressaltar que a estrutura estudada já está sendo recuperada pelo órgão público responsável. O resultado do estudo mostrou que o viaduto em destaque apresentava-se em más condições de manutenção, em estado bastante crítico devido a problemas como: corrosão em armaduras e deterioração no concreto com exposição das ferragens em parte da estrutura, necessitando com urgência de intervenções, pois, todos esses sintomas associados com ação de diversos agentes agressivos presentes no ambiente comprometiam a sua vida útil.

Palavras-chave: viadutos, construções, manifestações patológicas, concreto armado.

\begin{abstract}
Viaducts are engineering structures considered "Work of Art" because they allow a road to transpose valleys and traffic routes in urban centers. These buildings are relevant to the urban environment, as they allow the user to connect to different locations within the city with a certain speed facilitating urban mobility. Thus, this article aims to address the pathological manifestations found in the pillars of reinforced concrete in an viaduct located in an important access route in the city of Salvador-BA, as well as discuss the possible origins and risks that can bring users, since security is compromised. The methodology used consisted of the bibliographic and documentary research technique, through the analysis of the problem, reflecting on the probable causes, consequences and forms of prevention in order to minimize such deteriorating actions. A visit was made "on site", in order to diagnose through visual inspection the pathologies that compromise the proper functioning of the structure. It is noteworthy that the structure studied is already being recovered by the responsible public agency. The result of the study showed that the highlighted viaduct was in poor maintenance conditions, in a very critical condition due to problems such as: corrosion in reinforcements and deterioration in concrete with exposure of hardware in part of the structure, urgently requiring interventions, because all these symptoms associated with the action of several aggressive agents present in the environment compromised their useful life.

Keywords: viaducts, constructions, pathological manifestations, reinforced concrete.
\end{abstract}




\section{INTRODUÇÃO}

Os grandes centros urbanos brasileiros possuem atualmente uma enorme quantidade de obras de arte especiais como pontes e viadutos. Em muitos casos o poder público não possui planos de manutenção preventiva para tais construções e, quando interditadas para obras de reforço ou restauro, causam transtornos viários. Diante deste quadro, é de extrema importância que os engenheiros, técnicos e estudantes de engenharia compreendam a importância das manutenções e, em casos extremos, estabeleçam critérios adequados para intervenções de restauro ou até mesmo reforço nessas estruturas que são as artérias das grandes cidades.

Do mesmo modo que o corpo humano necessita de exames médicos periódicos a fim de detectar problemas ou para diagnosticar uma enfermidade, analogamente, as estruturas também carecem de manutenção periódica e vistorias como aconselham as boas práticas de engenharia.

A NBR 7188 (2013) define que os viadutos são estruturas para transpor um obstáculo artificial (avenida, rodovia, entre outros). Vale ressaltar que essas edificações possuem grande valor no meio urbano, uma vez que permite ao usuário conectar-se a diferentes locais dentro da cidade com certa rapidez e facilita a mobilidade urbana. A construção dessas Obras de Artes Especiais (OEA's) é frequente em grandes cidades do nosso país, já que muitas delas apresentam um tráfego intenso.

De acordo com Laner (2001, p.3), "as pontes e viadutos das grandes cidades são verdadeiros equipamentos urbanos, indispensáveis para a vida cotidiana de suas populações porque, antes de tudo, definem os principais escoamentos de vias, articulando cruzamentos de grandes avenidas, encurtando caminhos e compensando acidentes geográficos". No entanto, os viadutos, são vítimas diariamente de ações que ocasionam esforços e inclusive deformações permanentes capazes de provocar consequências terríveis à durabilidade, resistência e utilização. Entre as ações destacam-se aquelas oriundas das cargas móveis geradas pelos veículos, da alternância de temperatura, ambientes com alto grau de agressividade e algumas em especial motivadas pela ação do homem. Para Helene (1992, p. 15):

[...] desde o início do emprego do concreto armado, criado na França em 1849 por Monier, as edificações, obras de arte, rodovias e demais construções têm suportado às mais diversas sobrecargas e ações do meio ambiente. Entretanto, o mesmo necessita receber manutenção sistemática e programada a fim de minimizar a ocorrência de manifestações patológicas, pois as mesmas acarretam redução da capacidade resistente podendo chegar ao colapso parcial ou total da estrutura.

Sendo assim, a degradação dos viadutos torna-se uma problemática difícil de impedir, ou seja, durante algum momento da sua vida útil poderá haver patologias devido também a fatores como a falta de inspeção, tipo de material utilizado, ausência de programas de manutenção preventiva e corretiva. Segundo Araújo (2019):

[...] as principais consequências da falta de manutenção de pontes e viadutos estão associadas além da diminuição da vida útil da estrutura, assim como a falta de manutenção das Obras de Artes Especiais (OAEs) gerando custos muito altos, pois, devido ao mau estado de conservação, as obras necessitam de manutenções e intervenções emergenciais, resultando em elevadas despesas com reparos e reforços.

Portanto, este trabalho tem como objeto de estudo um tema de suma importância, que diz respeito a mostrar um panorama do estado de conservação aparente de um viaduto localizado em uma relevante via de acesso na cidade de Salvador-BA, bem como discorrer sobre as principais patologias encontradas nesse bem público, decorrente da falta de manutenção. Por fim, é importante informar que a estrutura em estudo está em processo de recuperação estrutural mediante autorização dos órgãos público competente.

\section{METODOLOGIA}

A metodologia exposta neste trabalho consistiu na técnica de pesquisa bibliográfica e documental, através da análise do problema, refletindo sobre as prováveis causas, consequências e formas de prevenção de modo a minimizar tais ações deteriorantes. Foram realizadas visitas "in loco", no período de um ano, a fim de vistoriar e diagnosticar por meio de inspeção visual as patologias existentes nos pilares de sustentação do viaduto e que, consequentemente, comprometem o bom funcionamento da estrutura. 
Nesta perspectiva, utilizamos como referencial teórico as seguintes normas: ABNT NBR 7188 (Carga móvel rodoviária e de pedestres em pontes, viadutos, passarelas e outras estruturas), ABNT NBR 9452 (Inspeção de pontes, viadutos e passarelas de concreto - Procedimento), Decreto $N^{\circ} 13.251$ de 27 de setembro de 2001 - Dispõe sobre a manutenção preventiva e periódica das edificações e equipamentos públicos ou privados no município de Salvador, Revista trimestral Ed. 38/2012 do CREA-BA e Manual de Recuperação de Pontes e Viadutos Rodoviários - DNIT, dentre outros artigos relevantes ao tema.

\section{ESTADO DO VIADUTO ANTES DA RECUPERAÇÃO ESTRUTURAL}

Mesmo com o necessário cumprimento das Normas Brasileiras e alguns cuidados construtivos que são tomados, a ocorrência de patologias nas estruturas ainda se faz presente no cotidiano do profissional de engenharia civil, tendo em vista que os materiais utilizados nos métodos construtivos podem ter sua origem em diversas fontes. E quando essas patologias ocorrem, em muitos casos, não são de simples diagnóstico e nem de tão fácil explicação de uma possível causa para a estrutura danificada.

De modo geral, as informações apresentadas sobre a situação do viaduto foram baseadas nas análises das manifestações patológicas presentes nos mesmos antes do seu processo de recuperação estrutural. A situação mais preocupante era a existência de alguns pilares em avançado estado de corrosão, com as armaduras totalmente expostas e representando riscos para seus usuários à medida que poderia provocar o colapso do equipamento.

Ainda de acordo com Helene (1992), os sintomas mais comuns, com grande ocorrência nas estruturas de concreto são: as fissuras, as eflorescências, as flechas excessivas, as manchas no concreto aparente, a corrosão de armaduras e os ninhos de concretagem (segregação dos materiais constituintes do concreto).

Os pilares da estrutura apresentavam graves problemas, entre eles destacam-se as armaduras com as ferragens expostas e em crescente estado de corrosão. O que compromete ainda mais essa situação é que muitas delas estavam expostas e sofriam, diariamente, com a presença de agentes agressivos, entre eles o oxigênio (ar), umidade (água), dióxido de carbono $\left(\mathrm{CO}_{2}\right)$, os nitratos $\left(\mathrm{NO}_{3}\right)$, e outras substâncias que podem acelerar o processo de deterioração do material. Esses agentes podem ser encontrados na atmosfera, em águas do mar, dejetos orgânicos e na própria urina humana ou até mesmo motivados por falhas que podem ocorrer ao longo da realização das etapas de concepção, execução e utilização.

Conforme o manual do DNIT (2010), as causas da deterioração das estruturas encontradas nas obras de artes especiais podem ser classificadas em: fatores intrínsecos, resultantes do tráfego rodoviário, ambientais, resultante do tipo e intensidade da manutenção, correlacionados à atividade humana. Os fatores intrínsecos estão relacionados com a estrutura. Entre eles destaca-se a idade e qualidade do concreto, qualidade dos agregados e, principalmente, o fator água/cimento. Em relação os fatores resultantes do tráfego rodoviário são de natureza externa e são ligados a utilização da estrutura, sobretudo, pelo grande aumento dos efeitos dinâmicos. Já os ambientais são referentes à classe de agressividade ambiental onde a estrutura esta localizada. Por fim, o fator manutenção é o decisivo que influencia a durabilidade das estruturas.

Frente a esses agentes causadores dos problemas patológicos, citados no parágrafo anterior, outro ponto a ser destacado é que eles são evolutivos e com o passar do tempo tendem a intensificar-se, podendo acarretar uma série de problemas associados nas estruturas.

Do ponto de vista econômico, é válido destacar que os gastos de uma recuperação estrutural variam em função do tempo de manifestação e detecção da patologia. Entretanto, na visão de Helene (1992) as correções serão mais duráveis, mais efetivas, mais fáceis de executar e muito mais baratas quanto mais cedo forem executadas. Corroborando com essa opinião, Leonel Borba (2018), em reportagem publicada na website do CREA-BA, diz que a partir do momento em que não se faz manutenção periódica, a recuperação se torna bem mais cara aos cofres públicos e, no caso dos viadutos, a segurança começa a ser menor.

Diante dessa situação, o grande obstáculo relacionado a esses tipos de edificações na capital baiana está ligado diretamente a uma ausência na cultura de manutenção desses equipamentos no município. No entanto, ao desenvolver a pesquisa, verificou-se a existência da Lei Municipal $n^{\circ} 5.907$ de 23 de janeiro de 2001 que, no Artigo $1^{\circ}$ decreta a manutenção das edificações e equipamentos em Salvador. 
A legislação também permite a constatação do estado de conservação das edificações e equipamentos públicos e privados, a partir dos laudos de vistoria, além de estabelecer a adoção de medidas saneadoras para sua utilização segura que visem evitar danos materiais e principalmente pessoais ocasionados por acidentes devido à depreciação dos elementos que compõe as construções.

Já no âmbito nacional, a NBR 9452:2016 (Inspeção de pontes, viadutos e passarelas de concreto - Procedimento) especifica os requisitos exigíveis na realização de inspeções em pontes, viadutos e passarelas de concreto e na apresentação dos resultados destas inspeções.

Dentre os fatores importantes apresentados na Norma e que merecem atenção estão os relacionados aos tipos de vistoria:

a) Vistoria Cadastral

b) Vistoria Rotineira

c) Vistoria Especial

Diante do exposto, percebe-se que, mesmo com a existência de legislações e normas, faltam ações mais efetivas de politicas públicas objetivando o estado de conservação e manutenção dos viadutos. Logo mais serão mostradas fotos que retratam a falta de gestão dos mesmos.

\section{CARACTERIZAÇÃO DA OBRA DE ARTE}

A revista do CREA-BA (2012) aponta que o número de pontes, pontilhões e viadutos de Salvador totalizam em torno de 110 edificações e muitas delas têm a necessidade reparos e manutenção. Nesse contexto, é válido destacar que os viadutos de Salvador são de grande relevância em função do seu uso coletivo dentro do contexto urbano. Ainda de acordo com a publicação, não precisa ser especialista para detectar os problemas de infraestrutura encontrados na capital baiana. A deficiência é ainda mais gritante no que se refere às obras d'arte especiais, como viadutos que apresentam fissuras expostas, desgaste do concreto, oxidação e infiltrações.

Segundo estudo realizado pelo Sindicato da Arquitetura e da Engenharia - Sinaenco (2018) "Infraestrutura de Salvador: prazo de validade vencido", cujo objetivo era alertar as autoridades e a sociedade sobre a urgência e importância da adoção por parte dos órgãos públicos das três esferas de poder (federal, estadual e municipal) de uma política permanente de manutenção, com destinação de recursos financeiros, humanos e tecnológicos para essa questão.

Com base na pesquisa de campo e inspeção visual realizada pelos autores deste estudo, em 2018, identificou-se que parte da estrutura da obra de arte analisada não apresentava um bom estado de conservação.

O viaduto em estudo está localizado no centro da cidade de Salvador, via de acesso que liga o bairro dos Barris ao Dique do Tororó, na Avenida Vasco da Gama. As figuras 1 e 2 retratam a vista frontal e a localização do viaduto respectivamente.

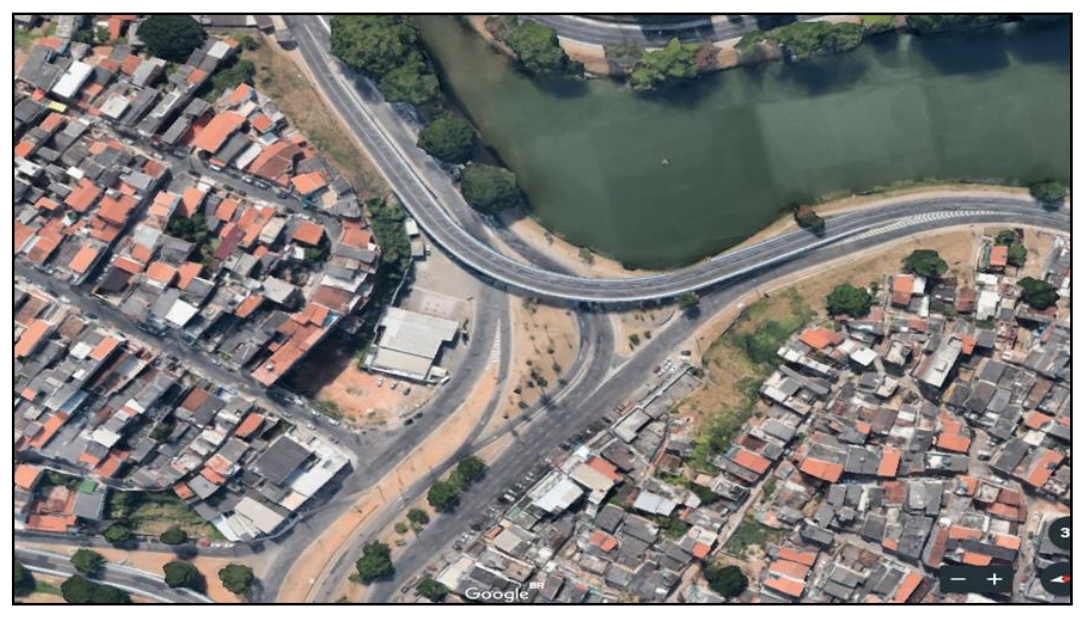

Figura 1: Vista frontal do viaduto em análise Fonte: Os autores 


\section{CBPAT 2020 \\ CONGRESSO BRASILEIRO DE PATOLOGIA DAS CONSTRUÇÕES \\ DE 15 A 17 DE ABRIL | FORTALEZA - CE}

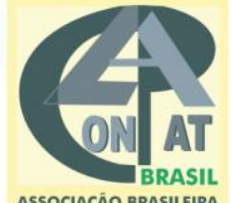

ASSOCIAC̄AO BRASILEIRA CONSTRUÇOES

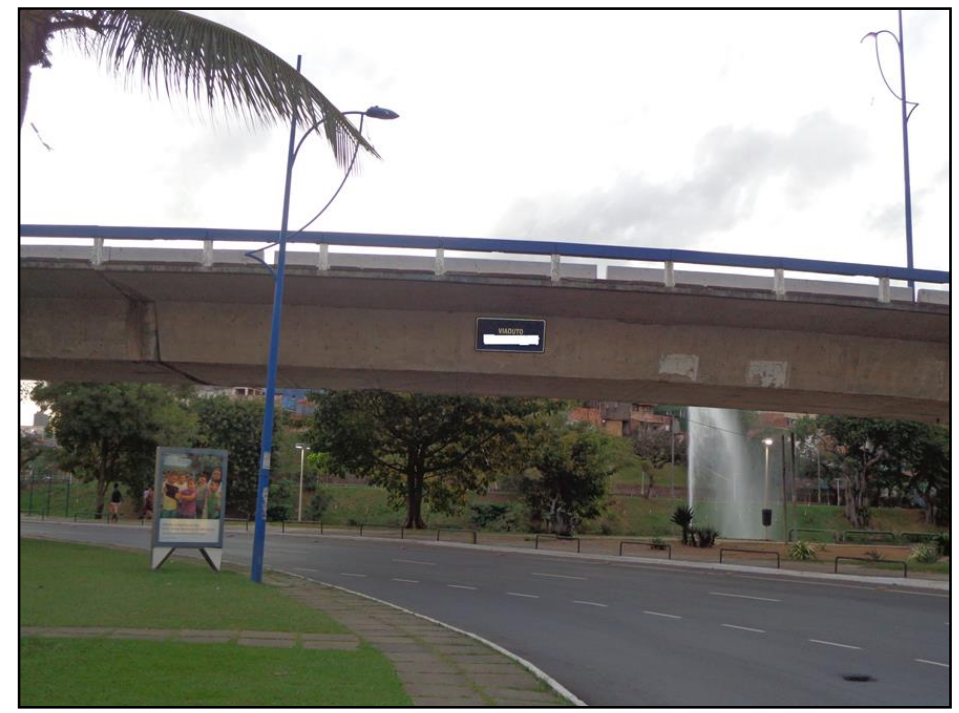

Figura 2: Localização do viaduto em análise Fonte: Google Earth

Na imagem acima percebe-se a existência da represa próxima ao viaduto, conhecida como Dique do Tororó. No local é muito comum a prática de atividades esportivas e lazer pela população soteropolitana.

\subsection{Manifestações patologicas encontradas}

Com base nas investigações de campo realizada, neste tópico serão apresentados os registros fotográficos das manifestações patológicas encontradas no viaduto, suas prováveis causas e possíveis formas de prevenção.

\subsubsection{Armaduras expostas e corroídas}

As armaduras expostas e corroídas mostradas na Figura 3 foi o tipo de patologia em maior evidência na Obra de Arte em estudo. Esse tipo de anormalidade compromete a vida útil da peça (pilares), pois reduz a sua capacidade de resistência aos esforços solicitantes. Além disso, sua causa pode ser agravada ainda mais quando há exposição do material com agentes nocivos presentes no ambiente em que está inserido.

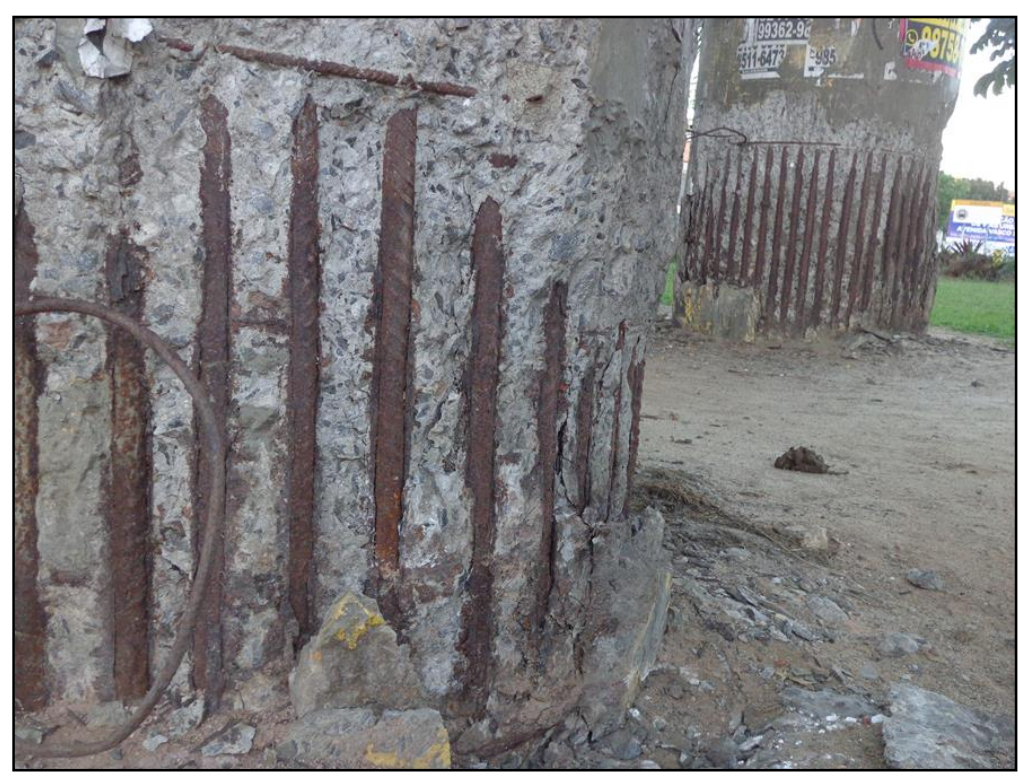

Figura 3: Armaduras expostas e corroídas Fonte: Os autores 
De acordo com Helene (1992), "o fenômeno da corrosão de armaduras no concreto armado é considerado como um efeito cascata, pois começa com uma mínima fissura na superfície do elemento estrutural que, logo, irá favorecer a entrada de oxigênio e umidade até a ferragem e após essa situação inicia-se um processo muito difícil de ser controlado".

\subsubsection{Fissuras no concreto}

A presença de fissuras foi outro grande problema encontrado no viaduto, como é mostrado na Figura 4. Tais patologias são caracterizadas pela abertura de fendas ao longo da superfície da estrutura, e, através delas, ocorre o acesso dos agentes agressivos.

Sabe-se que a fissuração no concreto armado pode ocasionar problemas, entre eles: comprometimento estético da estrutura, sensação de desconforto e insegurança aos usuários, redução da inércia da peça e corrosão das armaduras, que num estado avançado pode comprometer a estabilidade e segurança da estrutura.

Souza e Ripper (1998) destacam que a fissuração pode ser considerada a patologia que mais ocorre, ou pelo menos a que mais chama atenção dos proprietários. As causas das fissuras são várias, e podem ser desde uma fissuração devido à retração hidráulica, por variação de temperatura até as provocadas por conta da corrosão da armadura, como é o caso da estrutura do viaduto em estudo.

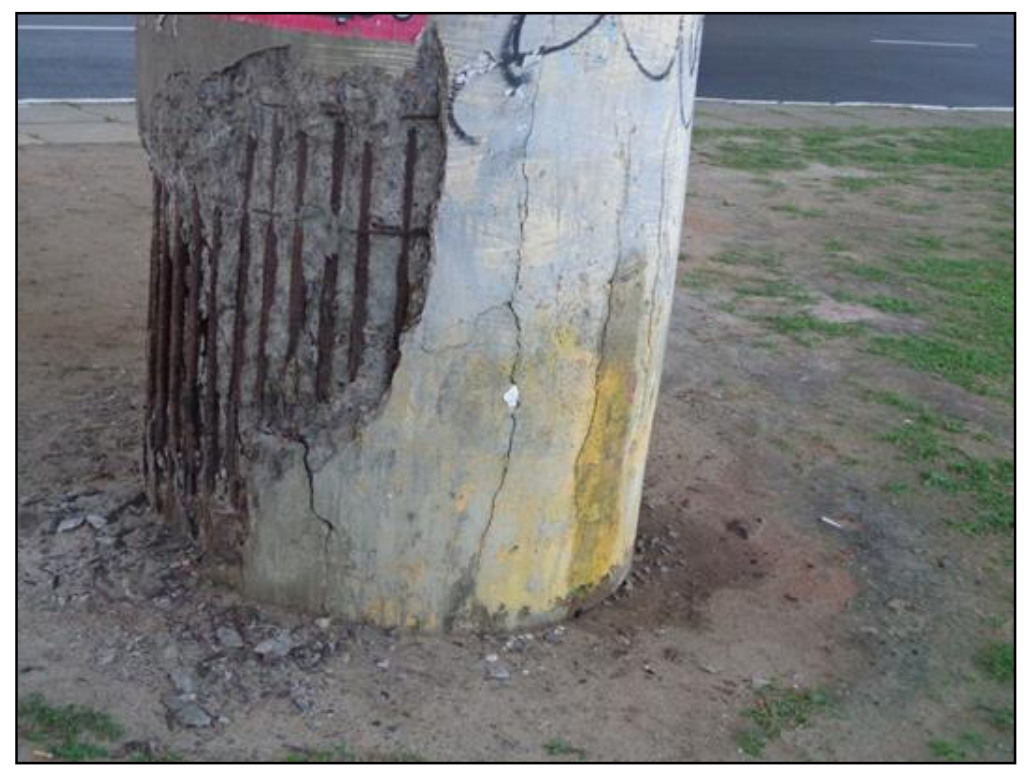

Figura 4: Fissuras no concreto devido à corrosão da armadura Fonte: Os autores

Nos pilares do viaduto, na Figura 4, também foram detectados locais marcados por manchas de urina. Esse mau hábito além de não ser correto ainda causa danos à estrutura, pois danifica o concreto, nesse caso, os pés dos pilares. A urina quando em contato com o concreto passa a ser um vetor altamente corrosivo para a armadura tendo em vista que tem a capacidade de penetrar por entre os poros presentes na superfície do concreto e, sendo assim, com o passar do tempo ocorrerá à expansão do aço devido à corrosão e, consequentemente, a fissura do mesmo.

\subsubsection{Desplacamento do concreto devido à corrosão}

Na estrutura foi possível identificar a ocorrência de desplacamento e deterioração do concreto, conforme a Figura 5. Sua ocorrência está relacionada ao intenso estado de corrosão das ferragens no viaduto que ocasionou em fissura, expansão do diâmetro do ferro devido às tensões geradas no interior do concreto e, consequentemente, ao desplacamento.

De acordo com Souza e Ripper (1998), ao oxidar-se, o ferro vai criando o óxido de ferro hidratado (Fe2O3 NH20). Para ocupar o seu espaço, esse óxido exerce uma pressão sobre o material que o confina de ordem de $15 \mathrm{MPa}$, suficiente para fraturar o concreto. 


\section{CBPAT 2020 \\ CONGRESSO BRASILEIRO DE PATOLOGIA DAS CONSTRUÇÕES \\ DE 15 A 17 DE ABRIL | FORTALEZA - CE}

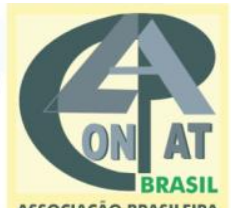

ASSOCIAC̄̃O BRASILEIRA CONSTRUÇOES

Abaixo, as Figuras 5 e 6, mostram a fácil remoção de um pequeno pedaço do concreto em avançado estado de desplacamento.

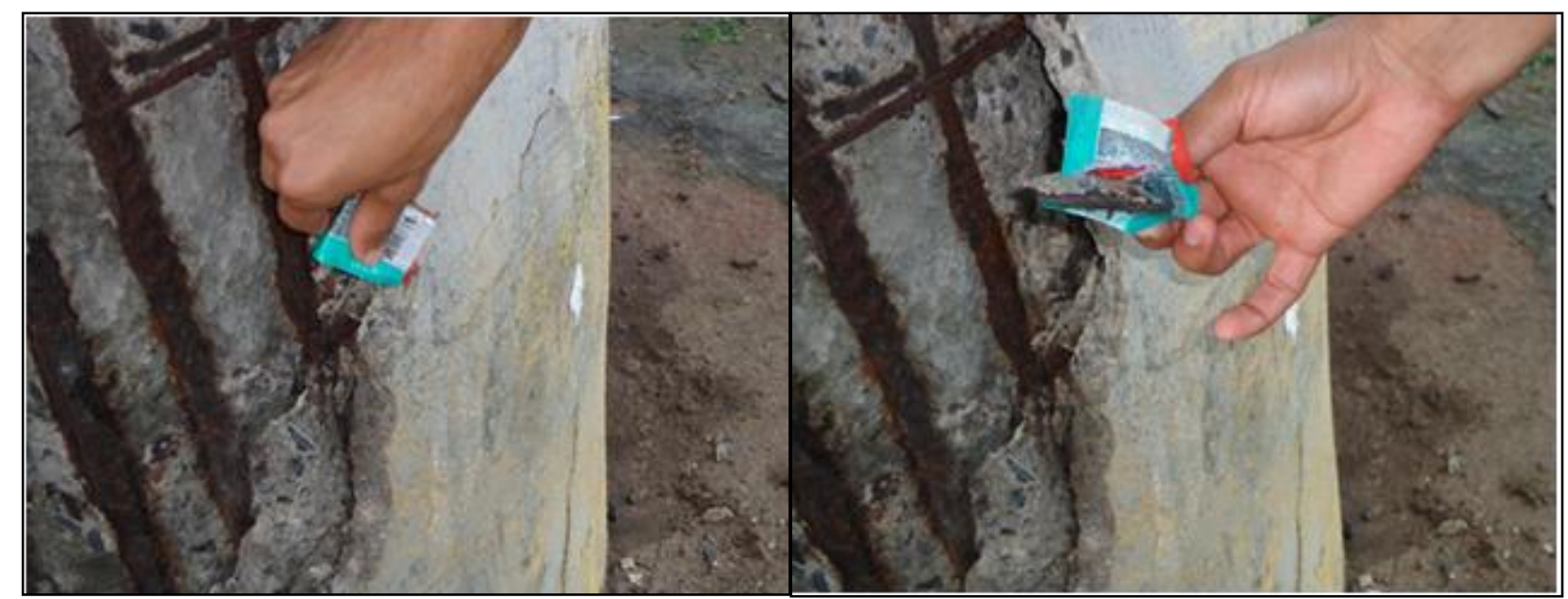

Figuras 5 e 6 - Detalhe do pilar do viaduto com desplacamento do concreto devido à corrosão Fonte: Os autores

\subsubsection{Corrosão seguida de um aumento considerável da seção da barra}

Na Figura 7, em outro ponto do viaduto, novamente constatou-se um grau intenso de corrosão da armadura. Foi possível observar que parte da amarração da armadura já se despedaçou. Como citado anteriormente, o nível de corrosão era tão intenso que o diâmetro da barra aumentou consideravelmente quando comparado com o diâmetro original.

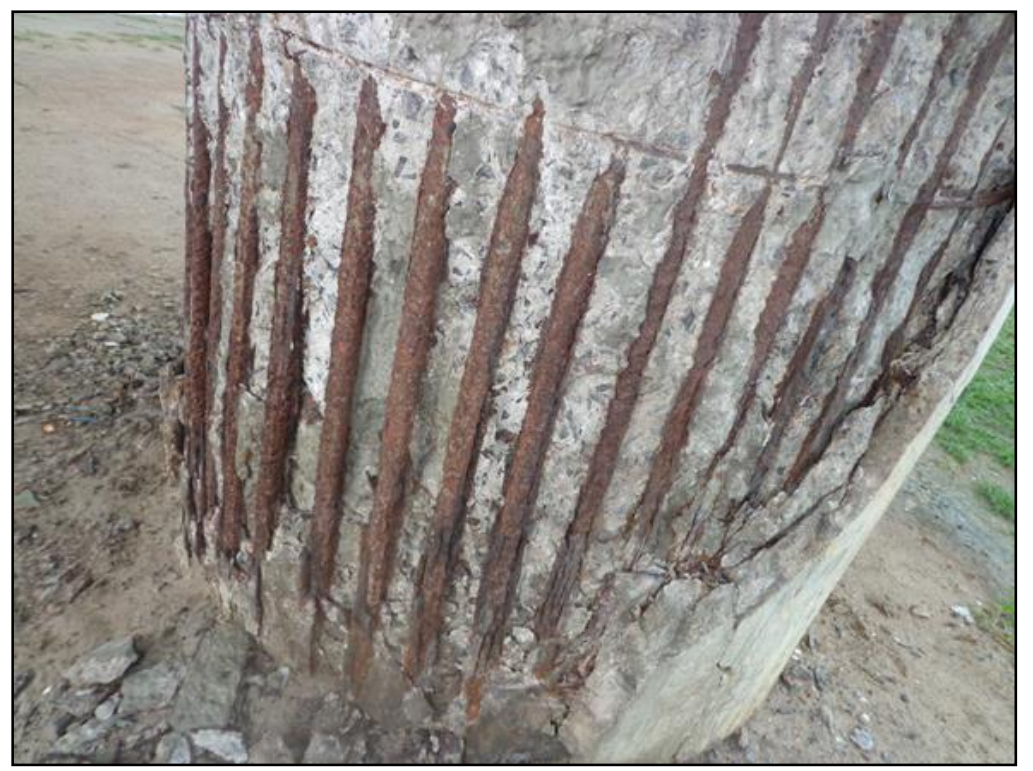

Figura 7 - Corrosão seguida de um aumento considerável da seção da barra Fonte: Os autores

\subsubsection{Avarias no pilar do viaduto vítima da ação do fogo}

Na figura 8 percebeu-se a ação do fogo nos pilares do viaduto investigado. Esse tipo de atividade, na maioria das vezes, é realizado por pessoas em situações de rua que não possuem moradia e ocupam os viadutos de forma irregular e, quando necessário, põem fogo próximo a estrutura do pilar para preparar suas refeições e esquentar-se durante o período de frio. 


\section{CBPAT 2020 \\ CONGRESSO BRASILEIRO DE PATOLOGIA DAS CONSTRUÇÕES \\ DE 15 A 17 DE ABRIL | FORTALEZA - CE}

ISBN 978-65-86819-05-2

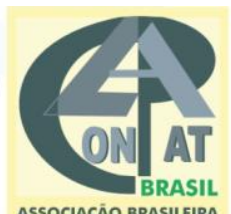

ASSOCIACÁB BRASILERA CONSTRUÇOES

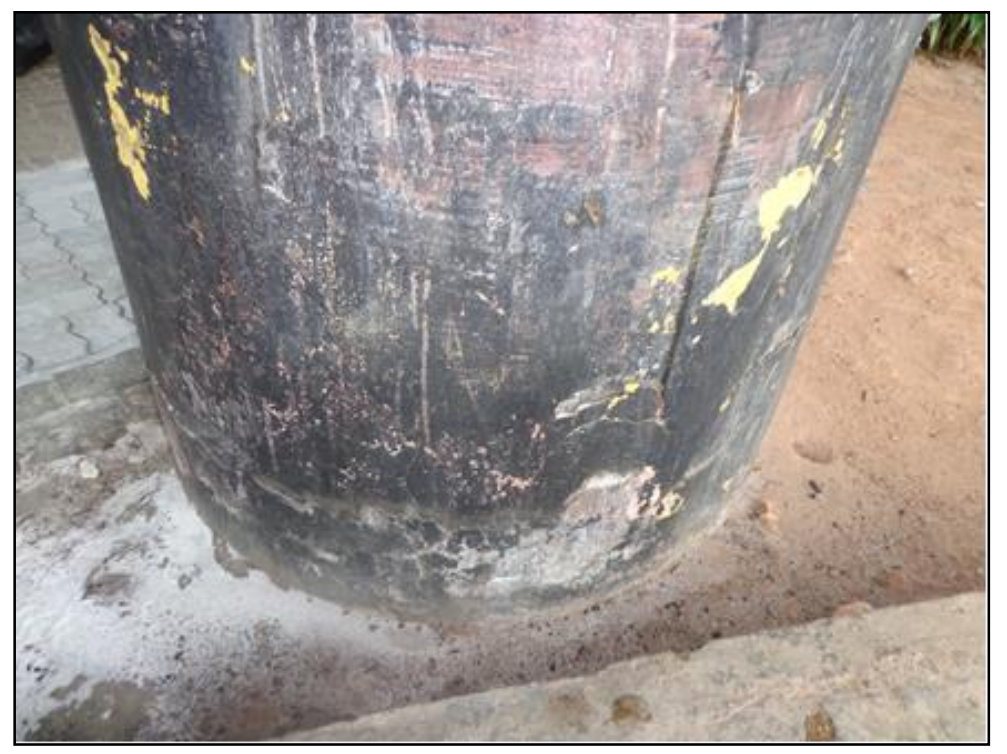

Figura 8 - Ação do fogo no pilar do viaduto

Fonte: Os autores

É notório que esse tipo de atividade proveniente, muitas de vezes, de ações humanas, pode provocar efeitos e danos na estrutura devido ao efeito da temperatura, haja vista que, em função do aumento e diminuição do calor de combustão, haverá a ocorrência de reação química e essas, por conseguinte, em longo prazo irá causar consequências no concreto. Em decorrência da ação do fogo, o lascamento do concreto é um tipo de patologia resultante desse processo.

Outras formas de deterioração são a ocorrência de esfarelamento superficial decorrente da ação da alta temperatura sobre a parte carbonatada do concreto e a fissuração proveniente da evaporação de água interna ao concreto e da dilatação térmica dos componentes e posteriores resfriamentos.

Os mesmos autores ainda destacam que a elevação da temperatura também interfere na coloração do concreto, variando de tons rosáceos nas temperaturas mais baixas, passando por tons cinza em temperaturas intermediárias e chegando a tons esbranquiçados e amarelecidos a altas temperaturas (MORALES; CAMPOS; FAGANELLO, 2011, p.50).

\subsubsection{Objetos depositados próximo aos pilares}

Além das patologias apresentadas, o que também chamou atenção na parte inferior do viaduto foi a presença de objetos deixados próximos a um dos pilares (Figura 9). Esse tipo de problema tem sido comum em viadutos do nosso país, portanto atenção especial deve ser dada para essa situação de modo que se evite o descarte e acúmulo de outros tipos de resíduos como entulhos, lixos domésticos e objetos inservíveis no geral.

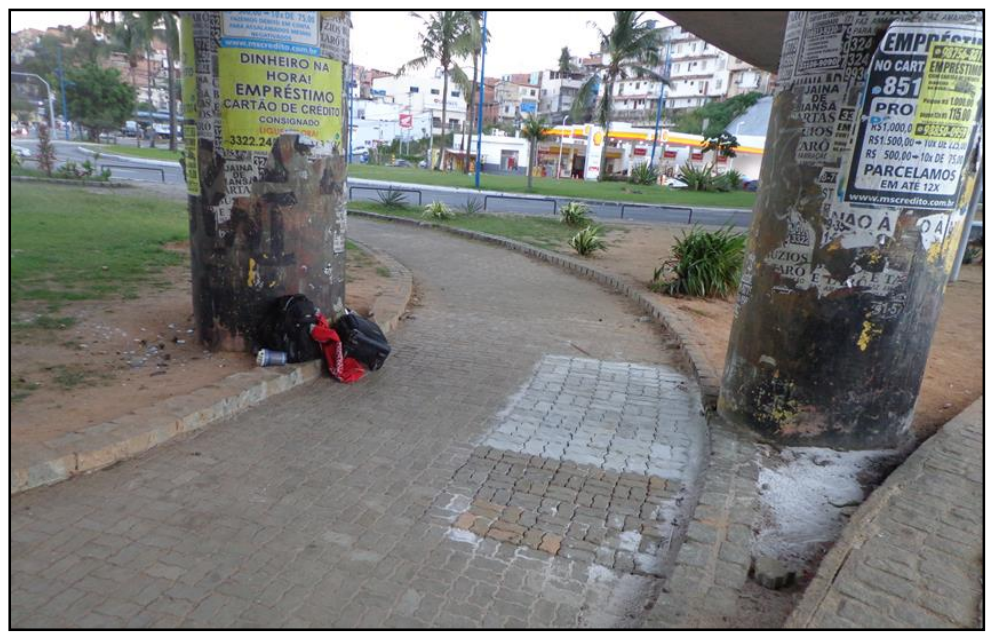

Figura 9 - Objetos acumulados debaixo do viaduto

Fonte: Os autores 
É importante a existência de ações preventivas de modo a impedir que o abandono de objetos se agrave e obstrua a livre movimentação de pedestres que passam pelo local.

Como forma de prevenção, a NBR 6118 determina critérios para melhorar a durabilidade da estrutura, destacando entre eles, atender um cobrimento mínimo estabelecido por norma, além de garantir a correta relação água/cimento, com a finalidade de garantir proteção às armaduras.

Outras medidas cabíveis, e de suma importância, têm relação com a inspeção e manutenção dessas construções, a fim de preservar a segurança e a vida útil para essas estruturas. No caso da estrutura investigada, a prática de inspeções periódicas por parte dos órgãos competentes minimizaria a ocorrência das patologias até aqui apresentadas no decorrer do trabalho e evitaria futuras tragédias.

No entanto, até a data presente da construção desse trabalho os pilares do viaduto já estavam em processo de recuperação estrutural, como mostra a Figura 10. Ao fundo da imagem observa-se a instalação de tapumes de madeira para isolar a área durante a execução de todo trabalho

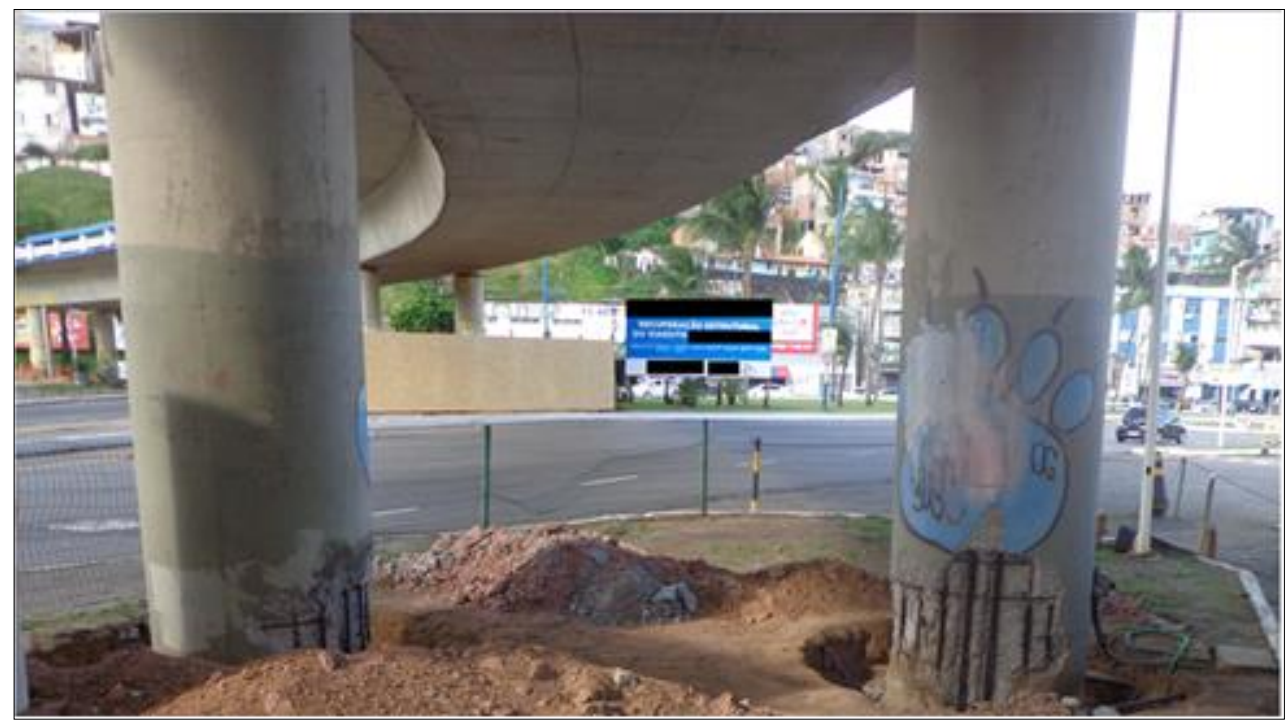

Figura 10 - Recuperação estrutural do viaduto Fonte: Os autores

De acordo com as informações presente na placa informativa o prazo de execução previsto para a realização da obra era de 6 meses. É válido informar que não foi possível obter maiores informações a respeito da execução da recuperação estrutural do viaduto, por isso não será especificado.

\section{CONSIDERAÇÕES FINAIS}

A realização do trabalho possibilitou a investigação das manifestações patológicas diagnosticadas nos pilares do viaduto localizado em Salvador (BA). Com base nos registros constatou-se que a corrosão das armaduras juntamente com o desenvolvimento em cadeia de outras problemáticas comprometeu seriamente a estrutura da edificação que foi estudada.

Partes das patologias diagnosticadas no viaduto poderiam ser evitadas se houvesse a adoção e maior cumprimento de medidas efetivas baseadas em um cronograma de manutenção preventiva e inspeções periódicas. A prática de manutenções preventivas, sem dúvida, contribui de forma a prolongar a vida útil, durabilidade das estruturas, reduz os custos da recuperação da obra e, sobretudo, evita tragédias como as que já ocorreram nos últimos anos em nosso País.

Através de uma observação própria, o que mais surpreende é o descaso por parte dos órgãos competentes, sobretudo em razão da falta de atenção fornecida a esses bens públicos presentes na cidade. Mesmo com a existência de Leis Municipais, que regulamentam ações baseadas em vistorias e manutenções, o que se vê ainda são Obras de Artes Especiais trabalhando sem o mínimo de condições favoráveis as quais foram projetadas, sendo vítimas do descaso. 
Deste modo, acredita-se que o trabalho atingiu o seu objetivo que era expor o estado de conservação antes de ser iniciada a recuperação estrutural da Obra de Arte, além de disseminar conhecimento a engenheiros, técnicos e estudantes de engenharia sobre a importância da prática de manutenções/vistorias nesses equipamentos (viadutos). E, por fim, dar suporte a comunidade científica que busca promover o debate, a troca de informação e o incentivo a produção literária, principalmente com realização de congressos, fóruns e palestras voltados para essa temática.

\section{REFERÊNCIAS}

ASSOCIAÇÃO BRASILEIRA DE NORMAS TÉCNICAS. NBR 6118. Projeto de estruturas de concreto Procedimento, 2014.

NBR 7188. Carga móvel rodoviária e de pedestres em pontes, viadutos, passarelas e outras estruturas Procedimento, 2013.

. NBR 9452. Inspeção de pontes, viadutos e passarelas de concreto - Procedimento, 2016.

BAHIA. Lei Municipal $\mathbf{N}^{\circ}$ 13.251. Dispõe sobre a manutenção preventiva e periódica das edificações e equipamentos públicos ou privados, no âmbito do município de Salvador e dá outras providências. Disponível em: https://leismunicipais.com.br/a/ba/s/salvador/decreto/2001/1325/13251/decreto-n-13251-2001-dispoe-sobre-aregulamentacao-da-lei-n-5907-de-23-de-janeiro-de-2001-e-da-outras-providencias. Acesso em: 13 out.2019.

CREA-BA. Crea faz vistoria em viadutos de Salvador. Disponível em: $<$ http://www.creaba.org.br/noticia/4061/Creafaz-vistoria-em-viadutos-de-Salvador-.aspx>. Acesso em: 22 out. 2019.

Edificações - Deterioração urbana. Disponível em:< http://www.creaba.org.br/Artigo/311/Edificacoes-Deterioracao-urbana.aspx>. Acesso em: 22 out. 2019.

. Desgastes nas alturas: falta de manutenção compromete viadutos de Salvador. Revista do CREA/BA, $\mathrm{n}^{\circ} 38$, jan.fev.mar, 2002. Disponivel em: < http://www.creaba.org.br/Imagens/FCKimagens/032012/Revista\%20Crea\%20ed\%2038.pdf>. Acesso em: 19 mar. 2019.

HELENE, Paulo R. L. Manual para reparo e proteção de concreto. 2ª ed. São Paulo: Pini, 1992.

Corrosão em armaduras para concreto armado. São Paulo: Pini: Instituto de Pesquisas Tecnológicas, 1986.

LANER, F.J. Manifestações Patógicas nos Viadutos, Pontes e Passarelas do Município de Porto Alegre. 2001. 157 f. Dissertação (Mestrado) - Curso Engenharia Civil, Universidade Federal do Rio Grande do Sul, 2001. Acesso em: 19 mar. 2019.

Manual de recuperação de pontes e viadutos rodoviários. 1. ed. Rio de Janeiro, 2010.

MORALES, D.; CAMPOS, A.; FAGANELLO, A.M.P. Ação do fogo sobre os componentes do concreto. Revista Semina: Ciências Exatas e Tecnológicas, vol. 32, número 1, 2011, Londrina. Disponível em:< http://www.uel.br/revistas/uel/index.php/semexatas/article/view/4057>. Acesso em: 01 dez.2019.

PINHEIRO, Catarina de Nazaré Pereira.; BARBOSA, Adriene Rodrigues.; REIS, Victória Dias.; DE OLIVEIRA , Felipe Ramos. Análise de Manifestações Patológicas em um Viaduto Localizado no Centro da Cidade de Belém -PA. In: Anais. X Congresso Brasileiro de Pontes e Estruturas, 2018, Rio de Janeiro. Disponível em: <http://www.abpe.org.br/trabalhos2018/199.pdf>. Acesso em: 08 ago. 2019.

IPT. Pontes e Viadutos. Instituto de Pesquisas Tecnológicas. São Paulo, 07 de jan. de 2019. Disponível em: <https://tecnoblog.net/247956/referencia-site-abnt-artigos/>. Acesso em:12 out.2019.

SOUZA, Vicente Custódio de.; RIPPER, Thomaz. Patologia, recuperação e reforço de estruturas de concreto. São Paulo: Pini, 1998. 


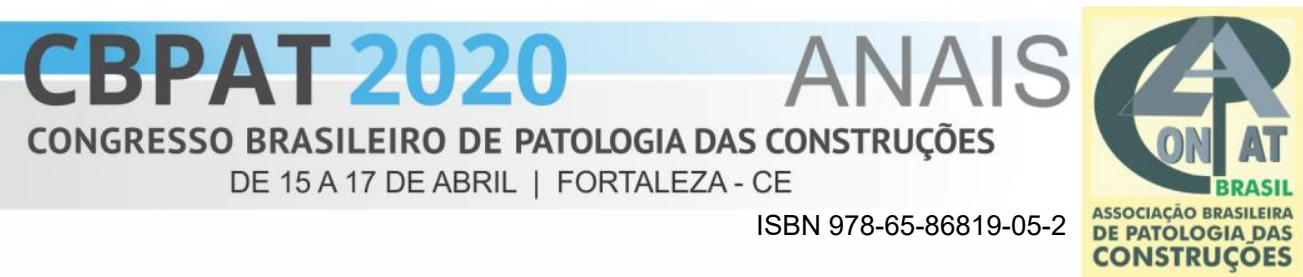

SINAENCO. Infraestrutura de Salvador: Prazo de Validade Vencido. 2018. Disponível em: < http://sinaenco.com.br/wp-content/uploads/2018/12/PVV-Salvador-2018.pdf >. Acesso em: 22 out.2019. 